\title{
Rock physics modeling to assess the impact of spatial distribution pattern of pore fluid and clay contents on acoustic signatures of partially-saturated reservoirs
}

\author{
Nisar Ahmed • Perveiz Khalid • Abdul Waheed Anwar
}

Received: 22 October 2014 / Accepted: 27 January 2015/Published online: 8 February 2015

(C) Akadémiai Kiadó 2015

\begin{abstract}
The identification of pore fluid type, saturation and distribution pattern within the pore space is of great significance as several seismic and petrophysical properties of porous rocks vary largely by fluid type, saturation and fluid distribution pattern. With the help of rock physics modeling, the impact of fluid saturation as well as fluid distribution pattern on seismic velocities, acoustic impedances and seismic amplitudes is estimated on porous rock of early Cretaceous Mississauga sands. For this purpose two saturation patterns: uniform and patchy saturations are considered within the pore spaces. The primary goal of this study is to understand the vertical and horizontal trends of numerous seismic parameters such as P-wave velocity $\left(V_{P}\right)$, S-wave velocity $\left(V_{S}\right)$, their impedances, $V_{P} / V_{S}$ ratio, bulk density $\left(\rho_{b}\right)$, seismic reflectivity etc. as a function of fluid saturation, saturation pattern (patchy or homogeneous), porosity $(\phi)$ and clay content. The results reveal that the seismic parameters and offset dependent amplitudes are very sensitive to pore fluid saturation and distribution patterns and physical properties. As the hydrocarbons (oil/gas) saturation increases, the compressional wave velocity decreases. P-wave velocity is $20-40 \%$ higher in case of patchy saturation than of homogeneous saturation. Similarly, reservoir porosity and clay matrix control the elastic response of porous rock due to which seismic velocities decrease with increase in porosity and clay content.
\end{abstract}

Keywords Rock physics - Fluid substitution - Homogeneous and patchy saturation · Fluid phases · Angle dependent reflectivity

\section{Introduction}

Seismic velocities in porous rocks are one of the most important parameter which give the information about the lithology (Tatham 1982), pore pressure (Sayers 2006), porosity

N. Ahmed $\cdot$ P. Khalid $(\square)$

Institute of Geology, University of the Punjab, Lahore 54590, Pakistan

e-mail: perveiz.geo@pu.edu.pk

A. W. Anwar

Department of Physics, University of Engineering and Technology, Lahore, Pakistan 
(Berryman et al. 2002), pore aspect ratio (Wang 2000), pore shape (Kuster and Toksoz 1974), overburden pressure (Korneev and Glubokovskikh 2013), pore fluid type (Ahmed et al. 2014; Khalid and Ghazi 2013), fluid saturation (Khalid et al. 2014a) and fluid distribution pattern within the pore space (Dvorkin et al. 1999). For porous rock saturated with two phase fluids, one is liquid (oil, water or brine) and other is gas, two saturation patterns within in the pore space: uniform and patchy are considered. Saturation pattern of two-phase fluid has a substantial effect on seismic wave propagation as well as on seismic properties of the porous rock (Toms et al. 2007). Seismic properties of porous rocks are different for uniform saturation and patchy saturation.

In quantitative seismic, the effect of partial saturation on seismic parameters has taken lot of attention (Dvorkin and Nur 1998; Knight et al. 1998; Mavko and Mukerji 1998; Dvorkin et al. 1999; Toms et al. 2007; Khalid and Ghazi 2013; Khalid et al. 2014a). All these studies have a following common argument. When low frequency $\left(1-10^{2} \mathrm{~Hz}\right)$ seismic waves propagate through partially-saturated porous media, there is enough time to re-equilibrate wave induced pore pressure. Thus, in this quasi-static limit, the fluid saturation may be considered as homogeneous within the pore space, and the porous rock can be treated as saturated with a homogeneous fluid mixture. In this situation, the effective bulk modulus of rock-fluid composite is generally determined by using well-known Gassmann poroelastic formula (Gassmann 1951) in which the bulk modulus of two-phase fluid $K_{f}$ is estimated by Wood's volume average equation (Wood 1941). For Wood's averaging method two underlying assumptions must hold; (1) fluid phases must be distributed homogeneously within pore space and (2) liquid and gas phases are unrelaxed (Khalid et al. 2014b). The assumption 1 means that both phases are distributed in the form of very small patches such that the length of these patches is smaller than the wavelength of the propagating seismic waves or the frequency of the waves is very low. However, for larger patches or higher frequency of propagating waves, both phases do not have enough time to re-equilibrate the wave induced fluid flow, thus cause a velocity dispersion and attenuation much different than in case of homogenous saturation. In this situation, the Gassmann's model is applied on individual patch to calculate its saturated bulk modulus. Hill's formula (Hill 1963) can be used in combination of Gassmann's formula to determine the overall saturated bulk modulus $K_{G \mathrm{H}}^{*}$.

The aim of this research work is to asses seismic properties of clastic sands of Mississauga Formation by considering homogeneous and patchy fluid saturation pattern. We also have analyzed how the change in seismic parameters at shale/brine sand, shale/oil sand and shale/gas sand interface control the variation in reflection amplitudes which is further used to discriminate hydrocarbon fluids. Finally the effect of physical properties of reservoir rock like porosity, clay content etc. on acoustic signature is also estimated.

\section{Quantitative work flow for rock physics analysis}

Rock physics quantify the effect of physical properties of reservoir rocks on seismic properties when $\mathrm{P}$ and $\mathrm{S}$ waves physically pass through rocks and establish a link between compressional wave $\left(V_{P}\right)$, shear wave $\left(V_{S}\right)$ and bulk density $\left(\rho_{b}\right)$ to the compressibility, rigidity, porosity, permeability, pore fluid type and saturation, saturation pattern, formation temperature and pressure. To develop a link between seismic and elastic parameters with physical properties of reservoir rock, we have performed fluid substitution modeling (FSM), which is an important part of rock physics analysis. The complete algorithm of FSM is described below. 


\subsection{Formulation of fluid substitution modeling (FSM)}

For low frequency seismic modeling of reservoir rock, the Gassmann's (1951) poroelastic model is frequently used to demonstrate the link among effective bulk modulus of fluid saturated rock $\left(K^{*}\right)$, bulk modulus of solid matrix $\left(K_{o}\right)$, drained rock $\left(K_{d}\right)$, and to the adiabatic modulus of pore filled fluids $\left(K_{f}\right)$. We adopted this poroelastic model for an isotropic and homogeneous clastic reservoir whose properties are given in Table 1. Mavko et al. (2009) represented the Gassmann's relation in the following form as

$$
\frac{K^{*}}{K_{o}-K^{*}}=\frac{K_{d}}{K_{o}-K_{d}}+\frac{K_{f}}{\varphi\left(K_{o}-K_{f}\right)}
$$

where $\phi$ is the reservoir porosity. Since, the effective shear modulus $\left(G^{*}\right)$ is not affected by the nature and amount of pore fluids, therefore Gassmann's model assumes $G^{*}=G_{d}$, where $G_{d}$ is the shear modulus of rock frame. The $K_{f}$ of saturating fluids mixture is determined by using Wood's average relation (Wood 1941). This method deals the mixture of fluids (e.g. liquid or gas) as two separate phases; hence $K_{f}$ is taken as the iso-stress average of the phase modulus by the volume fraction.

$$
K_{f}^{W}=\left[\frac{S_{w}}{K_{w}}+\frac{1-S_{h y d}}{K_{h y d}}\right]^{-1}
$$

Here $K_{w}$ and $K_{\text {hyd }}$ are the adiabatic bulk moduli and $S_{w}$ and $S_{h y d}$ are the volume fractions of water (may be brine) and hydrocarbons (oil or gas) phases respectively. The bulk modulus oil, gas and brine are computed using the empirical relations proposed by Batzle and Wang (1992).

Table 1 Reservoir parameters used in Gassmann fluid substitution modeling modified (from Khalid et al. 2014b)

\begin{tabular}{ll}
\hline Mississauga formation & Well L-30 \\
\hline Reservoir interval & $2,638-2,662 \mathrm{~m}$ \\
Average reservoir temperature $(\mathrm{K})$ & 389.55 \\
Average effective pressure $(\mathrm{MPa})$ & 26.234 \\
Fluid parameters & \\
Specific gravity of gas & 0.60 \\
Insitu gas density $\left(\mathrm{g} / \mathrm{cm}^{3}\right)$ & 0.143 \\
Bulk modulus of gas $(\mathrm{GPa})$ & 0.0552 \\
Oil API & 47.60 \\
Insitu oil density $\left(\mathrm{g} / \mathrm{cm}^{3}\right)$ & 0.739 \\
Gas to oil ratio $(\mathrm{Litre} / \mathrm{litre})$ & 191.7 \\
Bulk modulus of oil $(\mathrm{GPa})$ & 0.939 \\
Insitu density of brine $\left(\mathrm{g} / \mathrm{cm}{ }^{3}\right)$ & 1.178 \\
Bulk modulus of brine $(\mathrm{GPa})$ & 3.16 \\
Rock parameters & 37 \\
Bulk modulus of quartz $(\mathrm{GPa})$ & 21 \\
Bulk modulus of clay $(\mathrm{GPa})$ & 2.65 \\
Density of quartz $\left(\mathrm{g} / \mathrm{cm}^{3}\right)$ & 2.58 \\
Density of clay $\left(\mathrm{g} / \mathrm{cm}^{3}\right)$ & \\
\hline
\end{tabular}


Seismic velocities in reservoir rocks do not depend only on the saturation but also on the spatial distribution of fluid phases e.g. saturation pattern. A problem with Gassmann-Wood (GW) approach is that, it only valid if fluid phases (in case of mixed phase) are uniformly distributed at small scale but in contrast if the saturation is patchy over large scale the above approach fails to model the exact seismic response at the passage of seismic waves (Mavko and Mukerji 1998; Khalid et al. 2014a).

So to model the effect of heterogeneous (patchy) distribution of fluid phases in reservoir rock on seismic properties Gassmann-Hill (GH) model (Hill 1963) is used.

$$
K_{G H}^{*}=\left[\frac{S_{w}}{K_{w}^{*}+4 / 3 G^{*}}+\frac{S_{h y d}}{K_{h y d}^{*}+4 / 3 G^{*}}\right]^{-1}-\frac{4}{3} G^{*}
$$

The above equation is also known as Gassmann-Hill $(\mathrm{GH})$ approach used to calculate the $K^{*}$ when the distribution pattern in reservoir rock is patchy. However the incompressibility of fluids can also be computed using Voigt (1910), Reuss (1929) and Hill (1963). The comparison of these methods is also made and discussed in Sect. 3.1. The aim of FSM is to compute seismic response (velocities) and bulk density at reservoir conditions like temperature, pressure, mineralogy, salinity content, porosity and pore fluids saturation (brine, oil or gas). Seismic velocities can be calculated using known muduli and bulk density as

$$
\begin{gathered}
V_{P}=\left(\frac{K^{*}+4 / 3 G^{*}}{\rho_{b}}\right)^{1 / 2} \\
V_{S}=\left(\frac{G^{*}}{\rho_{b}}\right)^{1 / 2}
\end{gathered}
$$

where the bulk density of saturated rock as a function of porosity, fluid $\left(\rho_{f}\right)$ and matrix density densities $\left(\rho_{o}\right)$ is given

$$
\rho_{b}=\rho_{o}+\varphi \rho_{f}
$$

whereas,

$$
\rho_{f}=\sum_{i=1}^{N} S_{i} \rho_{i}
$$

Here $S$ and $\rho$ are the saturation and density of the fluid phase represented by sub index $i$ and $N$ is the total number of fluid phases. The above described relations are used to compute the effect of pore fluids on seismic response where various input parameters (e.g. drained bulk and shear moduli, bulk modulus of rock forming minerals, grains and fluid density, porosity etc.) are mandatory. These inputs are mostly measured in lab, but in case of nonavailability of lab measurements can be derived from logs data or be calculated via empirical relationships. For example $\phi$ can be computed from sonic or density logs. Similarly several numerical relations are available to estimate the drain rock modulus (Zhu and McMechan 1990; Murphy et al. 1993; Zinszner and Pellerin 2007). In the present FSM we have used the Murphy et al. (1993)'s relation:

$$
K_{d}=38.18\left(1-3.39 \varphi+1.95 \varphi^{2}\right)
$$


For the reservoir rock under investigation the average value of $K_{d}$ is about $14.28 \mathrm{GPa}$. To calculate the modulus of rock forming minerals, we must have knowledge about the mineral composition of rock, which is found from the laboratory measurements of core plugs or volume of clay can estimated from gamma ray log and remaining will be considered as quartz in case of clastic sedimentary rocks. Once the rock composition is known, $K_{o}$ is determined by using Voigt-Reuss-Hill (VRH) averaging (Hill 1952). For two phases it can be written as

$$
K_{o}=\frac{1}{2}\left[\left(f_{\text {clay }} M_{\text {clay }}+f_{\text {quartz }} M_{\text {quartz }}\right)\left(\frac{f_{\text {clay }}}{M_{\text {clay }}}+\frac{f_{\text {quartz }}}{M_{\text {quartz }}}\right)\right],
$$

whereas the $f$ and $M$ are the volume fraction and bulk modulus of rock forming minerals.

To model the effect of pore fluid saturation and spatial distribution on angle dependent reflectivity, we have computed the reflection coefficients as function incident angle by using exact Zoeppritz equation (1919) and then transferred these coefficients to K-tron $\mathrm{X}$-works seismic modeling engine using OIL script (Khan et al. 2010). Common depth point (CDP) gathers are produced by convolving these offset dependent reflection coefficients with Ricker wavelet.

\section{Results}

The above described fluid substitution model is applied on hydrocarbon bearing clastic silicate reservoir named Mississauga Formation of Early Cretaceous age widely present in Sable Basin of Canada. The reservoir rock is mainly composed of quartz (about 65-75\%), feldspar (10\%) and having volume of clay about 20-30\%. The mineralogical composition of reservoir sandstone is estimated by using wireline logs data (gamma ray log). The petrophysical evaluations of reservoir sand (Khalid et al. 2014b; Ahmed et al. 2014) indicate that it has good range of average porosity $(\sim 0.21)$ and permeability $(\sim 700$ millidarcy) and show very clear deviation on gamma ray log at shale-sand interface (sands have gamma ray $<60 \mathrm{API}$ ). The hydrocarbons found in the study area are characterized by light oil having API gravity 47.6-54.1 and gas have specific gravity about 0.6 , while the average water saturation $\left(S_{w}\right)$ in the reservoir is $34 \%$ and the remaining are the hydrocarbon fluids.

A complete set of wireline logs of well L-30 is available and used to extract the petrophysical parameters which are used further in rock physics modeling. FSM has been performed in the reservoir depth interval 2,638-2,662 $\mathrm{m}$.

\subsection{Effect of fluid saturation and pattern on seismic response}

One of the most essential and primary objective of rock physics modeling is to analyze the sensitivity of acoustic signature to pore fluids types, their saturation and distribution pattern as well. To map the effect of pore fluid type and saturation pattern on seismic properties in petroleum reservoirs, seismic data must be able to resolve incompressibility contrast among various reservoir fluids. Different reservoir fluids like oil, gas and brine have different compressibility (inverse of incompressibility). Since elastic and seismic properties of a saturated or partially-saturated reservoir are direct image of the pore fluid properties, therefore first we have analyzed fluid properties. In the Fig. 1a and b the bulk modulus of 
(a)

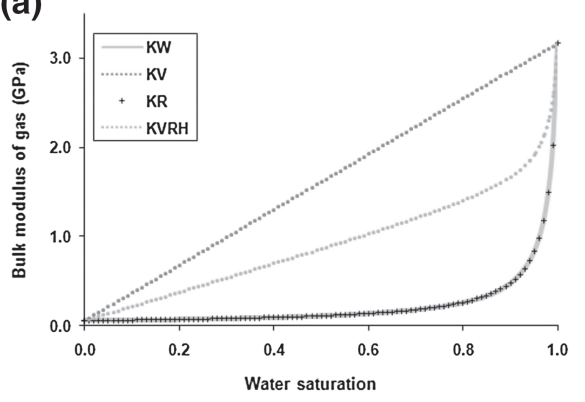

(c)

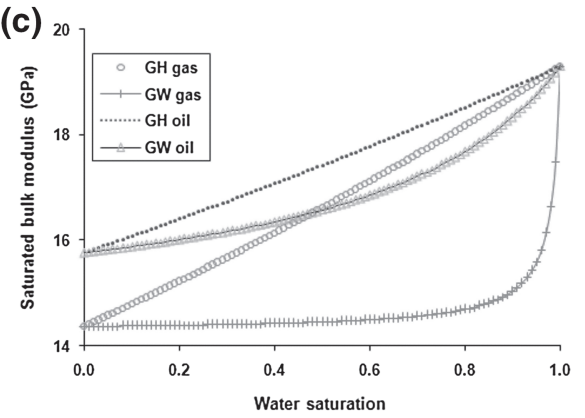

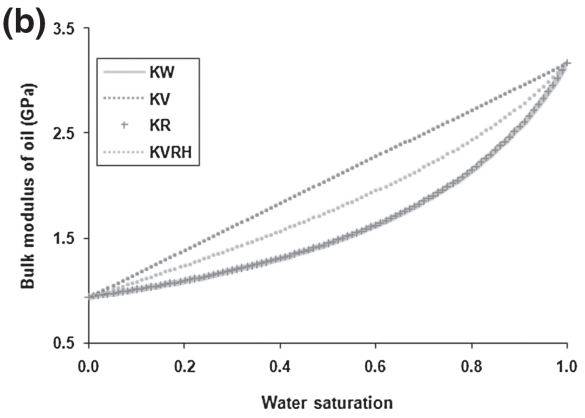

(d)

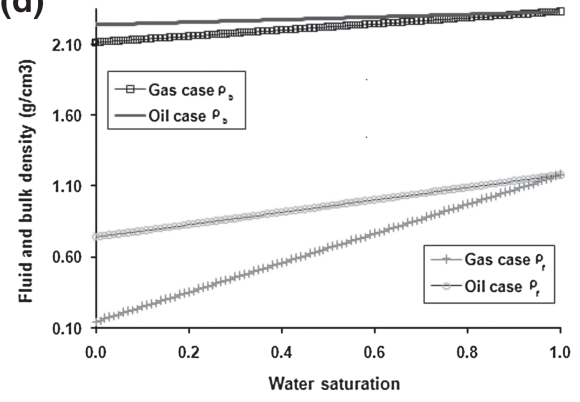

Fig. 1 Effect of fluid saturation patterns (homogeneous and patchy) on a bulk modulus of gas/water, b bulk modulus of oil/water, c effective bulk modulus of porous sand whose properties are given in Table 1 partially-saturated either with gas or oil, $\mathbf{d}$ density of gas, oil and bulk density of gas or oil saturated sand

gas and oil calculated via different empirical relations such as Voigt $\left(K_{V}\right)$, Reuss $\left(K_{R}\right)$, Wood $\left(K_{W}\right)$ and Hill $\left(K_{V R H}\right)$ are plotted respectively. It is clear from figures that brine has higher bulk modulus as compare to oil and gas therefore the bulk modulus of fluids decreases as saturation of brine reduces. This decrease is much higher in case of gas/water as compare to oil/water. $K_{V}$ marked the upper bond and $K_{W}$ or $K_{R}$ marked the lower bond of the bulk modulus of fluid mixtures. In case of mono phase fluids all empirical relations give same results. The Reuss method is also called iso-stress average that's why gives the similar results like Wood average method (Fig. 1a, b). While the Hill method is simply the arithmetic sum of Voigt and Reuss $K_{f}$. In Fig. 1c the effective bulk moduli computed via Gassmann-Wood (GW) (Eq. 2) and Gassmann-Hill (GH) (Eq. 3) at in situ conditions when reservoir is partially-saturated with oil or gas are plotted. The effective bulk moduli of partially-saturated rock follow the same trend as of fluids only with a difference of magnitude. The relation between saturated bulk modulus is developed at constant temperature, pressure, porosity $(21 \%)$ and average clay content $(20 \%)$. However, in case of patchy saturation saturated bulk modulus is higher as compared to homogeneous saturation which presents the upper bounds (Fig. 1c). In Fig. 1d fluid and bulk densities ( $\rho_{f}$ and $\rho_{b}$ respectively) for both oil and gas cases are plotted. As the hydrocarbon fluids replace brine $\rho_{f}$ and $\rho_{b}$ are decrease, it is because the hydrocarbon fluids (oil and gas) have lower densities as compared to brine. When same fluid is substituted in reservoir rock to find out the bulk density as a function of fluid saturation, the similar trend (like $\rho_{f}$ ) is followed (Fig. 1d).

The seismic velocities are directly linked to the saturated rock bulk modulus, shear modulus and bulk density (Eqs. 4 and 5). P-wave velocity as a function of water saturation 

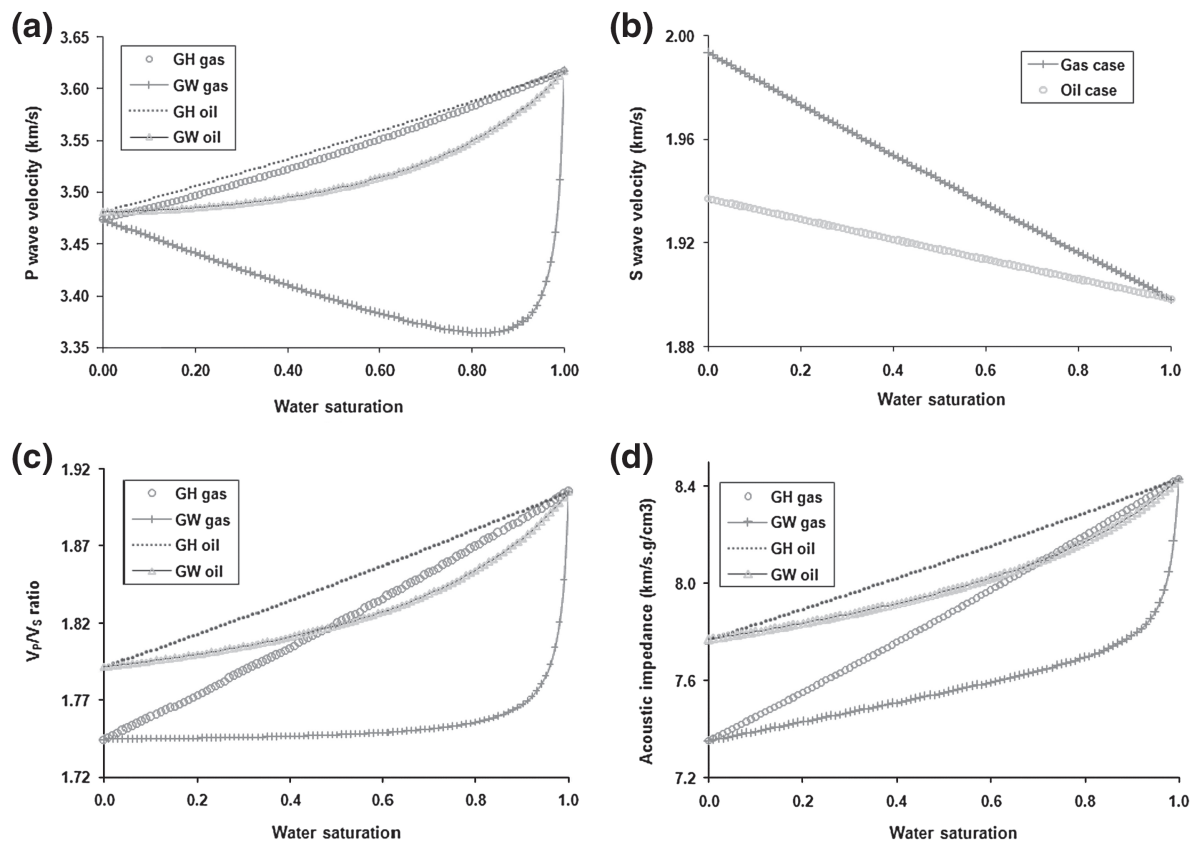

Fig. 2 Effect of fluid saturation patterns (homogeneous or partially) on a P-wave velocity of sand reservoir partially-saturated with gas and oil, b S-wave velocity, c $\mathrm{P}$ and $\mathrm{S}$ wave velocity ratio and $\mathbf{d}$ acoustic impedance. The properties of sand reservoir are given in Table 1

corresponding to homogeneous and patchy saturation for both oil and gas cases are presented in Fig. 2a. In case of patchy saturation compressional wave velocity is $20-40 \%$ higher than that of homogeneous pattern. For heterogeneous distribution $V_{P}$ decreases linearly as hydrocarbon fluids replace the brine but in case of homogeneous $(\mathrm{GW})$ pattern, small quantity $(10 \%)$ of gas dissolved in formation water drops the $V_{P}$ noticeably because of dramatic decrease in bulk modulus (Fig. 2a). Additional amount of gas does not decrease $V_{P}$ because the further change in $K^{*}$ is slight, but $V_{P}$ starts increase steadily when the effect of the drop off in the bulk density of reservoir exceeds the effect of the decrease in the $K^{*}$. On the other hand in reservoir rock fluids do not have any effect on $\mathrm{G}^{*}$ and $\rho_{b}$ reduces gradually with hydrocarbons saturation which leads to be progressive increase in $V_{S}$ with hydrocarbon saturation (Fig. 2b). Hydrocarbon saturation causes $V_{P}$ to decrease while the $V_{S}$ increases which leads to decrease in $V_{P} / V_{S}$ ratio when reservoir is fully saturated with gas as shown in Fig. 2c. Due to this reason $V_{P} / V_{S}$ ratio is one of the best indicators used to discriminate the formation fluids (especially gas reservoirs) and lithologies. $V_{P} / V_{S}$ ratio is always lower if fluid phases are homogeneously distributed because of lower compressional velocity in homogeneous case. Figure $2 \mathrm{~d}$ describes the spatial trend of acoustic impedance $\left(I_{P}\right)$ to pore fluid types and saturations for both GW and GH approaches. The decrease in $V_{P}$ and $\rho_{b}$ result the drop off $I_{P}$ for petroleum reservoirs saturated with oil or gas as compared to non-hydrocarbon fluids (water or brine). However the decrease in impedances for gas is more as compared to oil saturated rocks. Acoustic impedance response to distribution pattern is very resembling to $V_{P}$; it is higher in case of patchy saturation pattern as compared to homogeneous. 
3.2 Effect of fluid saturation and distribution pattern on angle dependent reflectivity

Seismic response to the pore fluid type, saturation and distribution pattern is the key factor to understand the behavior of reflection amplitudes as a function angles (AVA), which is widely used to discriminate the reservoir fluids. The angle dependent reflectivity is the function of three fundamental properties of reservoir rock: $V_{P}, V_{S}$ and $\rho_{b}$, which are (except $V_{S}$ ) directly analogous to fluid properties (as discussed in previous section). Due to this analogy the change in $V_{P}, V_{S}$ and $\rho_{b}$ result the variation in amplitude reflectivity with the change in incident angles at reservoir interface. The effect of fluids (oil, gas and brine), their saturation and homogeneous and patchy saturation pattern on reflection amplitudes at reservoir zone of Mississauga sand with upper shale are plotted up to $35^{\circ}$ in Fig. 3a. The reflection coefficients at $0^{\circ}$ incident angle are high (negative intercept) and its magnitude decreases with angles (positive gradient). The reservoir sand has lower seismic velocities and densities as compared to encasing shale thus have low impedance. The magnitude of coefficients is higher when the reservoir is fully saturated with gas as compare to oil and brine, while the brine has low than that of oil. Since the water saturation in reservoir zone is $34 \%$ so the reflection coefficients for homogeneous $(\mathrm{GW})$ and patchy $(\mathrm{GH})$ distribution for gas at saturation $\left(S_{w} \sim 34 \%, S_{g} \sim 66 \%\right)$ and oil $\left(S_{w} \sim 34 \%, S_{o} \sim 66 \%\right)$ are also plotted in Fig. 3a. the amplitudes in case of patchy saturation (for both cases water/gas and water/oil) are lower in comparison to homogeneous for both oil and gas case.

(a)

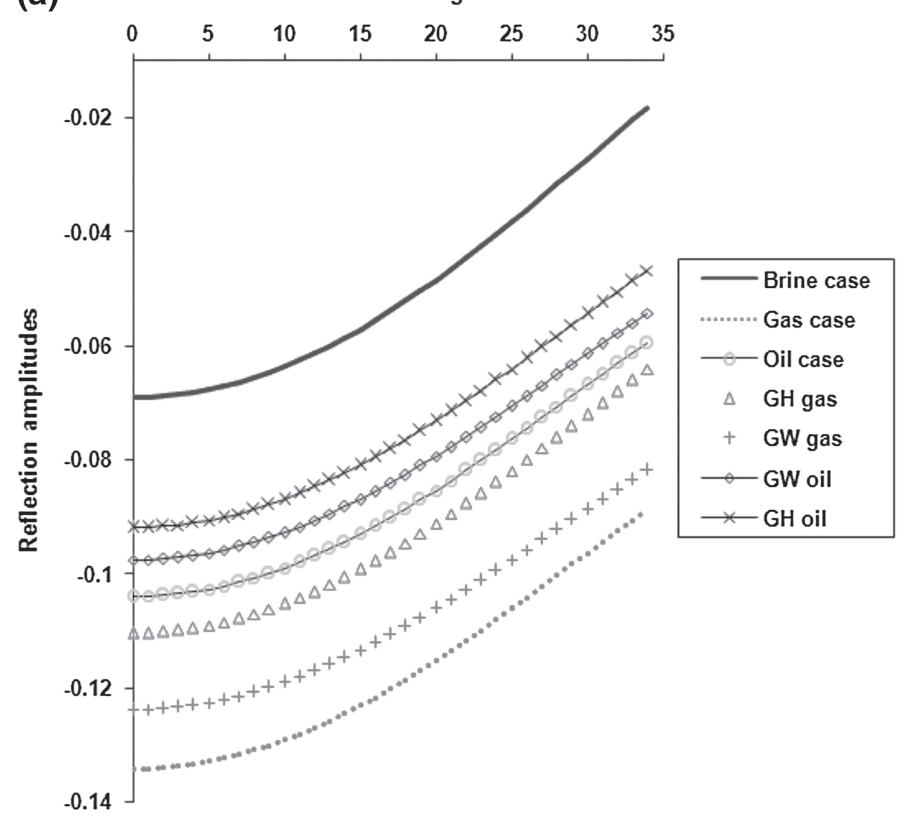

Fig. 3 a Angle dependent reflection coefficients of P-waves for sand reservoir saturated with brine or partially-saturated with oil and gas under patchy and homogenous saturation. b Angle dependent synthetic seismograms showing seismic response from sand reservoir saturated with brine and gas or partiallysaturated with either brine or gas at different saturation under patchy and homogenous saturation pattern 
(b)

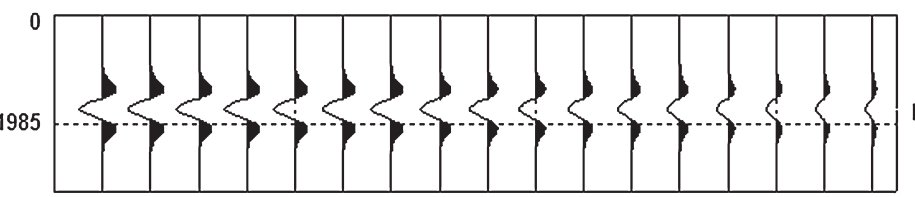

Brine case (100\%)

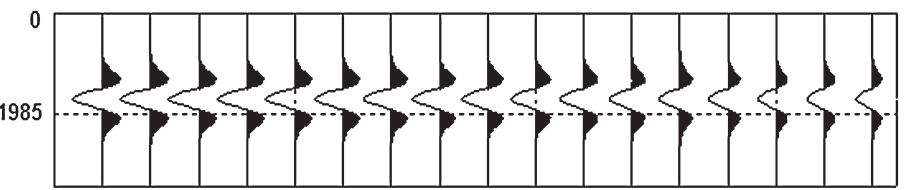

$\mathrm{GH}$ case

$66 \%$ oil, $34 \%$ brine

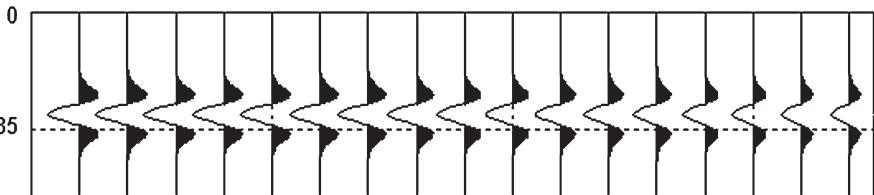

GW case

$66 \%$ oil, $34 \%$ brine

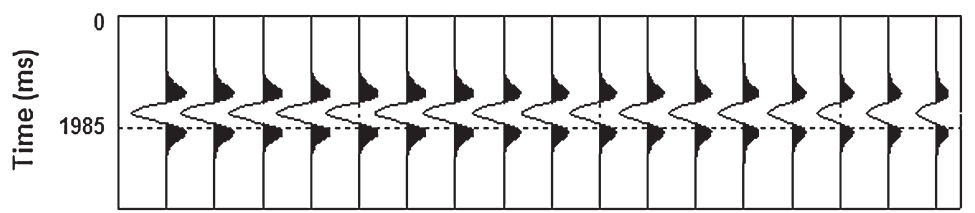

Oil case $(100 \%)$

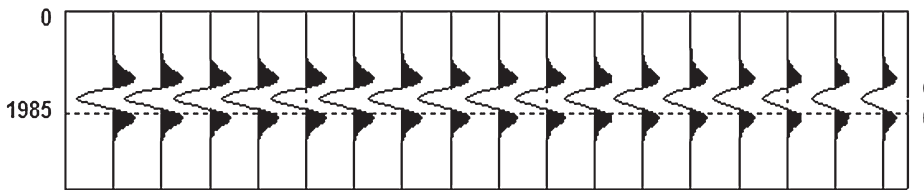

$\mathrm{GH}$ case

$66 \%$ gas, $34 \%$ brine

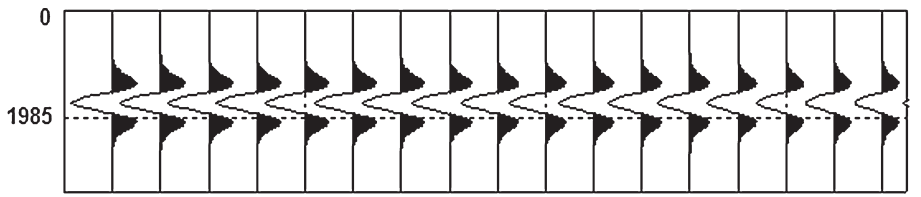

GW case

$66 \%$ gas, $34 \%$ brine

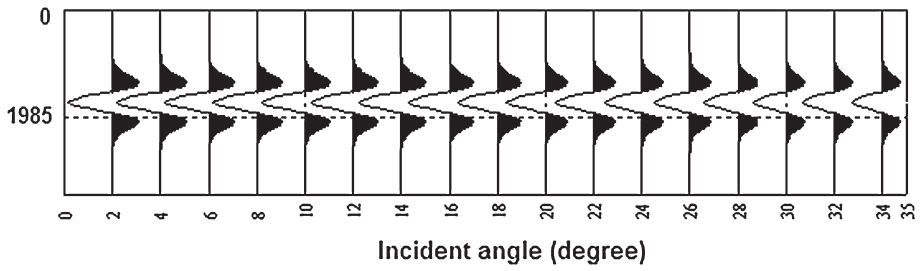

Gas case $(100 \%)$

Fig. 3 continued

The reflection amplitudes for water/gas (in both case e.g. GW and GH) are highly negative as compared to oil (for both distribution patterns: GW and $\mathrm{GH}$ )

In Fig. 3b, the synthetic CDP AVA models for single and binary phase fluids when they mixed uniformly $(\mathrm{GW})$ with each other at small scale and in contrast when fully saturated patches are surrounded by dry regions $(\mathrm{GH})$. The amplitudes are decreasing with angles and are higher when the rock is fully saturated with gas as compared to oil and brine cases. However the amplitudes are lower when multiple fluids have patchy distribution in comparison to uniform pattern. 


\subsection{Porosity effects on elastic moduli and seismic properties}

Rock physics diagnostic is an important tool which is widely used to explain the link between porosity and seismic parameters. However the porosity of rocks depends on the local digenesis e.g. non-contact and contact cementation which tends to reduce in pore volume. Elastic moduli depend on the reservoir porosity, as the porosity increases the elastic moduli become lower. In Fig. $4 \mathrm{a}, K_{d}$ and $K^{*}$ are plotted against porosity. At lower porosity both $K_{d}$ and $K^{*}$ have same values and fluid effect on bulk modulus cannot be analyzed. But as porosity increases $K^{*}$ starts to deviate from $K_{d}$ which also presents during Gassmann FSM, to analyze the fluids effect on elastic moduli and seismic signature reservoir rock should have high porosity. Similar trend can be observed in Fig. 4b which shows that bulk density reservoir is also strongly dependent on porosity. High porous media tends to lower the bulk density. The compression and shear wave velocities are also function of elastic moduli and bulk density that's why the change in porosity results variations in seismic signature also. Figure $4 \mathrm{c}$ demonstrates that a higher pore ratio result to decrease the seismic velocities and hence consequently acoustic $\left(I_{P}\right)$ and shear impedance $\left(I_{S}\right)$ also become lower (Fig. 4d). Because both acoustic and shear impedances are the scalar product of velocities $\left(V_{P}\right.$ and $V_{S}$ respectively) and density. But both velocities and impedances followed the same decreasing trend as a function of porosity. Sometimes

(a)

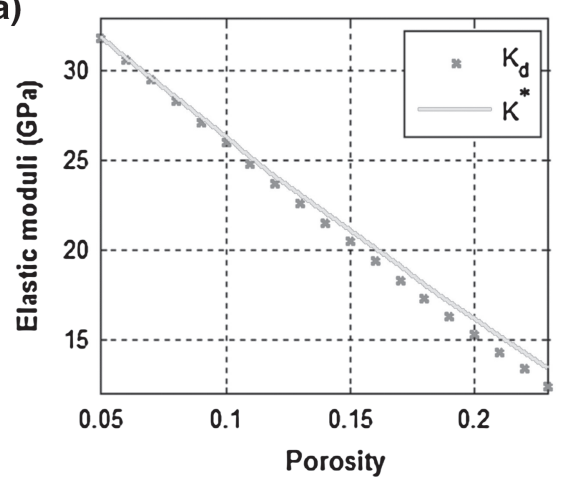

(c)

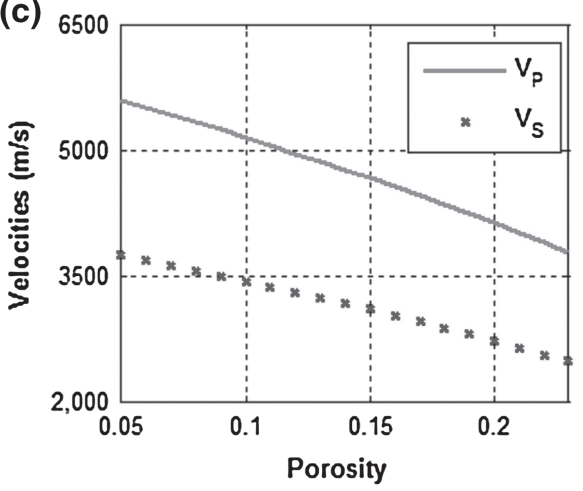

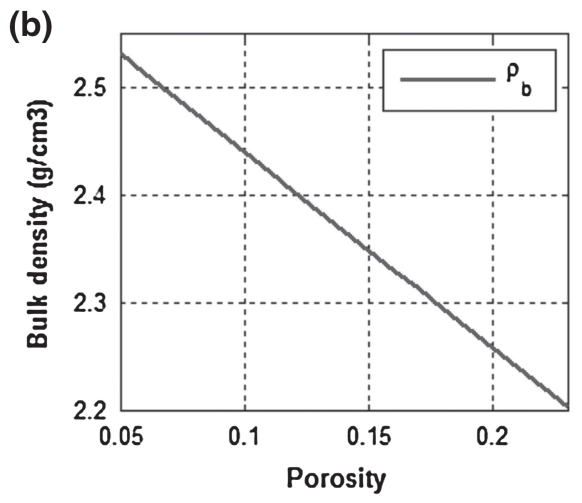

(d)

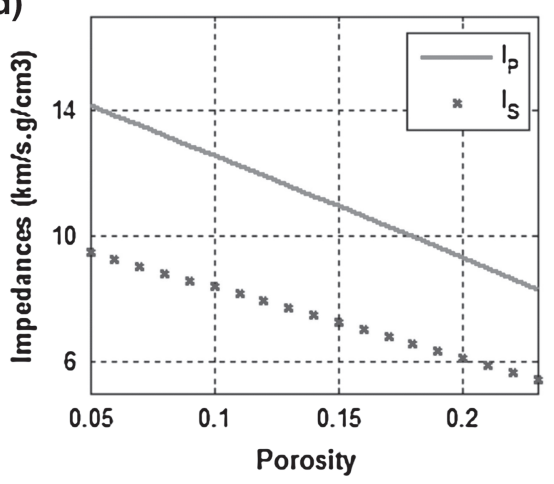

Fig. 4 Effects of reservoir porosity on a elastic moduli, b bulk density, $\mathbf{c} \mathrm{P}$ and $\mathrm{S}$ wave velocities and d acoustic and shear impedances at reservoir conditions in the study area 
velocity or impedance-porosity relation becomes more complicated because the velocity also depends pore shape. Rocks having low porosity with flat pores may have lower seismic signature than those having spherical pores with high porosity (Kuster and Toksoz 1974). So it needs to establish a porosity-velocity relation for each facies in reservoir because sedimentary rocks present a wide range pores.

\subsection{Effect of clay content on acoustic parameters}

The presence of clay content in reservoir rock has significant effect on the elastic and plastic characteristic of reservoir rocks. In Fig. 5a, the mineral and bulk density ( $\rho_{o}$ and $\rho_{b}$ respectively) are plotted against volume fraction of clay. Mineral density of clay is about $2.58 \mathrm{gm} / \mathrm{cm}^{3}$, as clay fraction replaces quartz (having density about $2.65 \mathrm{gm} / \mathrm{cm}^{3}$ ) both mineral and bulk density decreases (Fig. 5a). The saturated rock bulk modulus relates the clay content in a very similar manner as porosity. Clays always have lower elastic moduli as compared to quartz. That's why an increase in volume fraction of clay contents results to reduce the $K^{*}$ as demonstrated in Fig. 5b. On the other hand at $100 \%$ quartz (0\% clay) $K^{*}$ has higher values. Clays also have low bulk modulus as compared to quartz which leads to be reduce the seismic velocities $\left(V_{P}\right.$ and $\left.V_{S}\right)$ and impedances $\left(I_{P}\right.$ and $\left.I_{S}\right)$ as can be
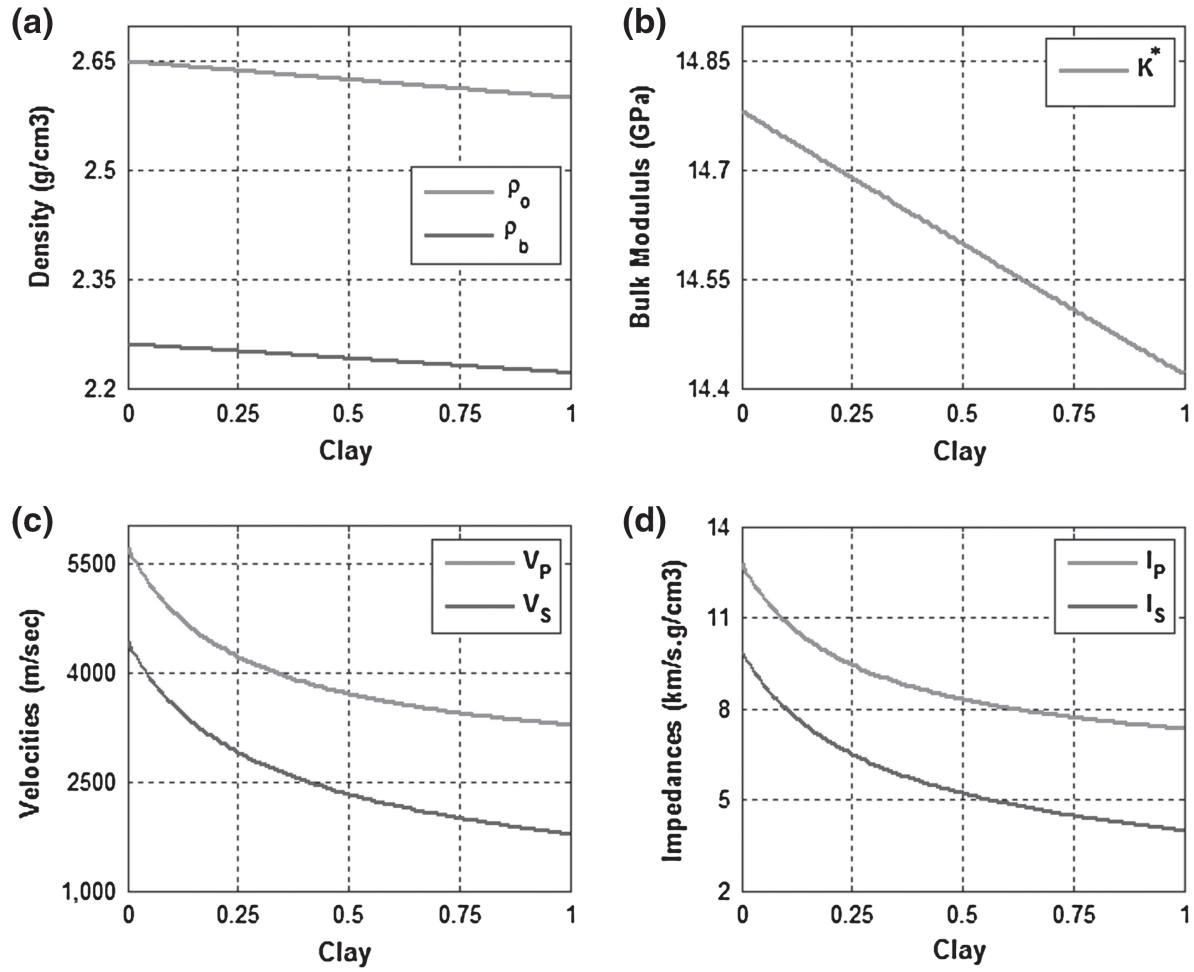

Fig. 5 Effects of volume fractions of mineral (clay/quartz) contents on a mineral and bulk density, b saturated rock bulk modulus, c compressional and shear wave velocities and their d impedances of Mississauga clastic sediments at in situ condition 
visualized in Fig. 5c and d. The trend of spatial variation in the seismic velocities and impedances as a function of shaliness is very similar (Fig. 5d).

\section{Conclusions}

Seismic properties of fluid saturated or partially-saturated porous rocks are affected in complicated way by several factors, such as rock forming minerals composition, porosity, fluid type, saturation, distribution pattern, elastic moduli, hydrocarbon properties like API gravity of oils, GOR etc. Mostly these factors are interlinked in such a way that when one factor changes it may results to change many others. Consequently, examining the effect of change in one constraint and keeping others constant becomes very important in understanding the application of rock physics to seismic interpretations. The seismic velocities are very sensitive to pore fluid type and saturation depends the compressibility of fluids. The more compressible fluids like gas have low compressional velocity and vice versa. Similarly in case of patchy saturation seismic velocities are higher as compared to uniform saturation. The acoustic velocities in light oil saturated rocks having high API gravities (high GOR) are always lower at same reservoir conditions. The gas saturated reservoir have high impedance contrasts, so high reflection amplitudes which leads the emerging possibility of differentiating the brine saturated reservoirs from hydrocarbon containing rocks. Rocks with high porosity and clay contents have lower elastic moduli, hence have low acoustic velocities.

\section{References}

Ahmed N (2013) Rock physics modeling and sensitivity analysis of AVO derived indicators to discriminate fluids and lithologies of Penobscot area, Nova Scotia, Canada. Dissertation, University of the Punjab

Ahmed N, Khalid P, Ghazi S, Anwar AW (2014) AVO forward modeling and attributes analysis for fluid's identification: a case study. Acta Geod Geophys. doi:10.1007/s40328-014-0097-x

Batzle ML, Wang Z (1992) Seismic properties of pore fluids. Geophysics 57:1396-1408

Berryman JG, Berge PA, Bonner BP (2002) Estimating rock porosity and fluid saturation using only seismic velocities. Geophysics 67:39-404

Dvorkin J, Nur A (1998) Time average equation revisited. Geophysics 63:460-464

Dvorkin J, Moos D, Packwood JL, Nur AM (1999) Identifying patchy saturation from well logs. Geophysics 64:1756-1759

Gassmann F (1951) Uber die Elastizitat poroser Medien. Vierteljahrsschr Natforsch Ges Zür 96:1-23

Hill R (1952) The elastic behavior of a crystalline aggregate. Proc Phys Soc Lond Ser A 65:349-354

Hill R (1963) Elastic properties of reinforced solids: some theoretical principles. J Mech Phys Solids 11:357-372

Khalid P, Ghazi S (2013) Discrimination of fizz water and gas reservoir by AVO analysis: a modified approach. Acta Geod Geophys 48:347-361

Khalid P, Brosta D, Nichita DV, Blanco J (2014a) A modified rock physics model for analysis of seismic signatures of low gas-saturated rocks. Arab J Geosci 7:3281-3295

Khalid P, Ahmed N, Khan KA, Naeem M (2014b) AVO-derived attributes to differentiate reservoir facies from non-reservoirs facies and fluid discrimination in Penobscot area. Geoscience J. doi:10.1007/ s12303-014-0048-0

Khan KA, Akhter G, Ahmad Z (2010) OIL-output input language for data connectivity between geoscientific software applications. Comput Geosci 36:687-697. doi:10.1016/j.cageo.2009.09.005

Knight R, Dvorkin J, Nur A (1998) Acoustic signatures of partial saturation. Geophysics 63:132-138

Korneev V, Glubokovskikh S (2013) Seismic velocity changes caused by an overburden stress. Geophysics 78:WC25-WC31

Kuster GT, Toksoz MN (1974) Velocity and attenuation of seismic waves in two-phase media-part I: theoretical formulations. Geophysics 39:587-606 
Mavko G, Mukerji T (1998) Bounds on low-frequency seismic velocities in partially saturated rocks. Geophysics 63:918-924

Mavko G, Mukerji T, Dvorkin J (2009) The rock physics handbook. Cambridge University Press, Cambridge

Murphy W, Reischer A, Hsu K (1993) Modulus decomposition of compressional and shear velocities in sand bodies. Geophysics 58:227-239

Reuss A (1929) Berechnung der fliessgrense von mischkristallen auf grund der plastizitatbedingung fur einkristalle. Zeitschrift furAnge-wandte Mathematik aus Mechnik 9:49-58

Sayers CM (2006) An introduction to velocity-based pore-pressure estimation. Lead Edge 25:1496-1500

Tatham RH (1982) $V_{P} / V_{S}$ and lithology. Geophysics 47:336-344

Toms J, Müller TM, Gurevich B (2007) Seismic attenuation in porous rocks with random patchy saturation. Geophys Prospect 55:671-678

Voigt W (1910) Lehrbuch der Kristallphysik. Teubner, Leipzig

Wang Z (2000) The Gassmann equation revisited: comparing laboratory data with Gassmann's predictions. In: Wang Z, Nur A (eds) Seismic and acoustic velocities in reservoir rocks, 3: recent developments. Soc Expl Geophys, pp. 8-23

Wood AB (1941) A textbook of sound. G. Bell and sons, London

Zhu X, McMechan GA (1990) Direct estimation of the bulk modulus of the frame in fluid saturated elastic medium by biot theory. In: 60th annual international meeting, SEG expanded abstracts, pp 787-790

Zinszner B, Pellerin FM (2007) A geoscientist's guide to petrophysics. Technip, Paris

Zoeppritz K (1919) Erdbebenwellen VIIIB, on the reflection and propagation of seismic waves. Göttinger Nachrichten 1:66-84 